Dermatology

Psychosomatics

Dermatologie

Psychosomatik

\section{Editorial}

Dermatol Psychosom 2002;3:60

\title{
Acne Perceptions
}

Some patients may have significant disease without apparent illness (e.g., hypertension) whilst others may be ill without apparent organic disease. Does it matter whether acne is a disease or not? The British Medical Journal published data showing that people were split roughly 50:50 on the question of whether acne was a disease or not [Smith, 2002]. Interestingly, in this study, secondary school students were less likely to rate acne as a disease than medical academics or general practitioners. These observations call into question concepts of normality as well as disease, especially as the survey showed that about $50 \%$ of teenagers consider it 'normal to have spots'.

From the dermatologist's point of view, acne is certainly regarded as a significant dermatological disease and clinically dermatologists see a wide spectrum of patients ranging from the cheerful and completely unconcerned individual with severe acne (usually brought to the doctor by his/her mother acne by proxy) to the psychologically disturbed, severely ill, depressed, dysmorphophobic individual with no insight and confidence whose whole life has totally collapsed because of a minute, more or less invisible pimple.

Studies have shown no correlation between the clinical severity of acne ratings made by the dermatologist and the patient. Clearly what matters is the patient's perception of severity which is determined by the premorbid personality, so that individuals with narcissistic personalities are particularly likely to develop severe depression as an accompaniment of absent or at most very mild skin disease.

Clinical management of patients with acne therefore demands not only a dermatological assessment of acne severity but also an assessment of the patient's quality of life, psychological status and the presence or absence of depression in particular. These data must be tempered by the patient's perception of his/her acne and its effect on that particular individual.

The article by Dr. Consoli [2002], on bridging the gap between doctor and patient, is particularly relevant in a wide spectrum of different patients presenting to the dermatologist with acne. Clearly, it is vital to avoid a strictly mechanistic approach in every patient. It may not be possible to bridge the gap between every patient and the doctor but every effort should be made.
The importance of good communication between the patient and, if necessary, other family members, and the physician is underlined by the fact that up to $10 \%$ of patients with acne have suicidal ideation and many dermatologists, unfortunately, have been involved in the management of patients with acne where the depression has been severe enough to lead to suicide. Other factors to consider are that significant depression may be present in up to $4.5 \%$ of adolescents and suicide in young males, whether they have acne or not, is an established clinical feature in most parts of the Western, or so called civilised, world.

A review on acne by Niemeier et al. [2002] and a paper on acne by Gieler [2002], both published in this journal, are therefore very timely. The management of patients with isotretinoin demands special care and Niemeier and his colleagues review the literature in their paper, noting an increase in the use of isotretinoin for mild and moderate acne. They advise that dermatologists should inform their patients about the possibility of developing a worsening of depression and patients should be advised to report any mood swings or depressive symptoms immediately to their medical advisors.

The physician looking after patients with acne or any patient with visible or chronic skin disease, must become skilled in doctor-patient relationships. It is no longer sufficient just to treat acne, but the whole patient and sometimes the family must be treated and treatment tailored to the patient's perception of his/her disease and the impact that disease is having on that individual patient's life. Clearly the doctor's objective view on the clinical severity and psychological disturbance matter little to the patient but even so these views should be recorded quietly in the case notes.

\section{J. A. Cotterill, Leeds}

\section{References}

Smith R: In search of 'non-disease'. BMJ 2002;324:883-885.

Consoli S: Bridging the gap between doctor and patient. Dermatol Psychosom 2002;3:88-91.

Niemeier V, Kupfer J, Gieler U: Acne is not a trivial disease! Psychosomatic aspects in routine therapy. Dermatol Psychosom 2002;3:61-70.

Gieler U: Acne. Dermatol Psychosom 2002;3:99-100.

\begin{tabular}{ll}
\hline KARGER & @ 2002 S. Karger GmbH, Freiburg \\
Fax +497614520714 & Accessible online at: \\
$\begin{array}{l}\text { E-mail Information@Karger.de } \\
\text { www.karger.com }\end{array}$ & www.karger.com/journals/dps
\end{tabular}

Prof. Dr. J.A. Cotterill

56 Broomfield

GB-Leeds 16LS 7AD (Great Britain) 